\title{
CONFIguRACIÓN de LA PRUEBA PERICIAL EN EL PROCESO PENAL COLOMBIANO*
}

\author{
José María Peláez Mejía** \\ Ronald Jesús Sanabria Villamizar****
}

Fecha de recepción: 27 de octubre de 2015

Fecha de evaluación: 15 de abril de 2016

Fecha de aprobación: 24 de agosto de 2016

Artículo de investigación

DOI: http://dx.doi.org/10.18359/prole.2726

Forma de citación: Peláez, J. M. \& Sanabria, R. J. (2017). Configuración de la prueba pericial en el proceso penal colombiano. Revista Prolegómenos Derechos y Valores, 20, 39, 105-124. DOI: http://dx.doi.org/10.18359/prole.2726

\section{Resumen}

Producto de la ley 906/2004 el régimen probatorio en materia penal sufrió cambios considerables no solo de orden procesal, los cuales son detectables a simple vista, sino sobre todo cambios de orden ideológico que reemplazaron el basamento principialístico de la anterior legislación. El presente artículo, teniendo como derrotero los principios probatorios del actual sistema de enjuiciamiento criminal en Colombia, la posición adoptada por la Corte Suprema de Justicia y la doctrina, pretende determinar los presupuestos de existencia o validez de la prueba pericial. Si bien el informe pericial es un elemento necesario, o en palabras de la Corte Suprema de Justicia un "germen de prueba", para la futura formación de la prueba pericial en la audiencia de juicio oral -puesto que permite el idóneo ejercicio de derechos como la confrontación, la contradicción y la defensa- su constitución y contenido dependen exclusivamente de la declaración del perito en audiencia.

\section{Palabras clave:}

Prueba pericial, declaración, prueba de referencia, informe pericial.

El presente artículo es un producto del proyecto de investigación "Efectividad en la implementación de la oralidad en el proceso civil", Grupo de Investigación de Derecho Procesal, Universidad Libre seccional Cúcuta, Colombia.

Abogado de la Universidad Libre seccional Cúcuta (Cúcuta, Colombia). Especialista en Combate del Crimen Organizado, Corrupción y Terrorismo de la Universidad de Salamanca, España. Magíster en Derecho Penal de la Universidad Libre seccional Bogotá (Bogotá, Colombia), candidato a magíster en Filosofía del Derecho y Teoría Jurídica de la Universidad Libre seccional Bogotá y candidato a doctor en Derecho en la misma institución. Docente investigador de la Universidad Libre seccional Cúcuta y actualmente decano de la Facultad de Derecho, Ciencias Políticas y Sociales de dicha universidad. Correo electrónico: josemaria.pelaez@unilibrecucuta.edu.co

... Abogado de la Universidad Libre seccional Cúcuta (Cúcuta, Colombia). Candidato a magíster en Derecho Penal de la Universidad Libre seccional Bogotá (Bogotá, Colombia) y candidato a magíster en Derecho Procesal Constitucional de la Universidad Nacional de Lomas de Zamora (Buenos Aires, Argentina). Docente investigador de la Universidad Libre seccional Cúcuta. Correo electrónico: ronald.sanabria@unilibrecucuta.edu.co 


\title{
CONFIGURATION OF THE EXPERT EVIDENCE IN THE COLOMBIAN CRIMINAL PROCEEDINGS
}

\begin{abstract}
Summary
As a result of law 906/2004, the probative system in criminal matters suffered considerable changes not only in procedural order, which are detectable to the naked eye, but mainly ideological changes that replaced the basis of principles of the previous legislation. This article, having the direction of the probative principles of the current criminal procedure system in Colombia, position taken by the Supreme Court of Justice and the doctrine, aims to determine the budgets of existence or validity of the expert evidence. Even though the expert report is a necessary element, or in words of Justice Supreme Court a "germ of test", for the future formation of the expert test in the audience of spoken trial -because it allows the suitable exercise of rights such as confrontation, contradiction and defense- its constitution and content depend exclusively on the declaration of the expert in the audience.
\end{abstract}

\section{Keywords:}

Expert evidence, declaration, reference evidence, expert report.

\section{CONFIGURAÇÃo da PROVA PERICIAL NO PROCESSO PENAL COLOMBIANO}

\begin{abstract}
Resumo
Produto da lei 906/2004 o regime probatório em matéria penal sofreu mudanças consideráveis não apenas de ordem processual, as quais são perceptíveis a simples vista, mas também, sobretudo mudanças de ordem ideológica que substituíram o embasamento de princípios da legislação anterior. O presente artigo, tendo como guia os princípios probatórios do atual sistema de instrução criminal na Colômbia, a posição adotada pela Corte Suprema de Justiça e a doutrina, pretende determinar os pressupostos de existência ou valor da prova pericial. Ainda que o laudo pericial seja um elemento necessário, ou nas palavras da Corte Suprema de Justiça um "germe de prova", para a futura formação da prova pericial na audiência de instrução -uma vez que permite o idôneo exercício de direitos como a confrontação, a contradição e a defensasua constituição e conteúdo dependem exclusivamente da declaração do perito em audiência.
\end{abstract}

\section{Palavras-chave:}

Prova pericial, declaração, prova de referência, laudo pericial.

\section{Introducción}

¿Debe o puede incorporarse en el juicio oral el informe del perito para que se produzca satisfactoriamente la prueba pericial o esta última se produce cabalmente con el solo dicho del testigo? La posibilidad o el imperativo de incorporación en el juicio oral del informe del perito es una de las dudas más recurrentes de magistrados, jueces, fiscales y defensores desde la entrada en vigencia del actual sistema de enjuiciamiento criminal colombiano (ley 906/2004).

Partiendo del problema jurídico compuestoalternativo propuesto, el objetivo del presente 
artículo es determinar si existe viabilidad jurídica para incorporar como medio documental o elemento constitutivo de la prueba pericial el informe escrito del perito o si por el contrario, ese ejercicio no es posible por constituir prueba de referencia inadmisible.

En caso de que sea afirmativo el primer punto, se estudiará si siendo factible la incorporación del informe pericial este acto constituye un requisito de validez de la prueba pericial, es decir, si es imperativa su incorporación para la constitución de la prueba pericial o meramente opcional.

Para mostrar una correcta génesis de dicho problema jurídico se hace necesario: (i) llevar a cabo una exposición de la principialística que entra en tensión con la resolución del mismo y (ii) enunciar los problemas jurídicos adyacentes al principal planteado aquí, porque solo a partir de su respuesta se podrá encontrar la claridad y suficiencia esperadas.

Esta investigación es de tipo "jurídico", utiliza para su desarrollo el método de la construcción de precedentes judiciales desde la perspectiva de su obligatoriedad. Se precisa que en Colombia operan tres tipos de precedentes: uno de obligación absoluta ${ }^{1}$ (generado únicamente por la Corte Constitucional colombiana en sentencias de control de constitucionalidad), otro de obligación semiabsoluta ${ }^{2}$ (tan solo hallado

Constitución Política de Colombia, artículo 243: "Los fallos que la Corte dicte en ejercicio del control jurisdiccional hacen tránsito a cosa juzgada constitucional. Ninguna autoridad podrá reproducir el contenido material del acto jurídico declarado inexequible por razones de fondo, mientras subsistan en la Carta las disposiciones que sirvieron para hacer la confrontación entre la norma ordinaria y la Constitución".

2 Constitución Política de Colombia, artículo 241: "A la Corte Constitucional se le confía la guarda de la integridad y supremacía de la Constitución, en los estrictos y precisos términos de este artículo. Con tal fin, cumplirá las siguientes funciones: (...) 9. Revisar, en la forma que determine la ley, las decisiones judiciales relacionadas con la acción de tutela de los derechos constitucionales". Este nombre de precedente de "obligación semiabsoluta" lo tomamos para asignarle una denominación a un estadio intermedio de vinculatoriedad del precedente ubicado entre la "obligación absoluta" y la "obligación relativa". en el alcance de los derechos fundamentales que fija la Corte Constitucional a través de la ratio decidendi en sus sentencias de tutela, por ejemplo, T-254/2006) y otro de obligación relativa ${ }^{3}$ (cuya génesis está en la Corte Suprema de Justicia y en la misma Corte Constitucional, según se explicará más adelante).

Este concepto de precedente es en gran medida diverso de la denominada jurisprudencia como criterio auxiliar ${ }^{4}$, ya que con base en el primero se presenta una vinculación absoluta (precedente de obligación absoluta), media (precedente de obligación semiabsoluta) o relativa (precedente de obligación relativa) para el funcionario jurisdiccional que fallará un determinado caso, mientras que con la segunda no se ocasionará ningún tipo de obligación o ligamen para el juez o tribunal encargado de resolver el problema jurídico en cuestión, siendo más bien una luz cuya función será la de darle una mayor visibilidad al sendero de la decisión última que va a ser próximamente tomada.

El nombre con el que comúnmente encontraremos a este tipo de jurisprudencia constitucional es el de "precedente de proyección doctrinal vinculante", según se establece en la sentencia C-539/2011 proferida por la Corte Constitucional. Sin embargo, optamos por asignarle el de "obligación semiabsoluta" porque tal denotación brinda mayor claridad sobre el "grado" de vinculatoriedad que tiene respecto a la toma de una decisión determinada.

3 Su fundamento y configuración lo encontraríamos en: Constitución Política de Colombia, artículo 234: "La Corte Suprema de Justicia es el máximo tribunal de la jurisdicción ordinaria y se compondrá del número impar de magistrados que determine la ley"; artículo 235: "Son atribuciones de la Corte Suprema de Justicia: 1. Actuar como tribunal de casación. Ley 153 de 1887. Art. 10. Artículo subrogado por el artículo 4. de la Ley 169 de 1889, el nuevo texto es el siguiente: 'Tres decisiones uniformes dadas por la Corte Suprema, como tribunal de casación, sobre un mismo punto de derecho, constituyen doctrina probable, y los jueces podrán aplicarla en casos análogos, lo cual no obsta para que la Corte varíe la doctrina en caso de que juzgue erróneas las decisiones anteriores'".

4 Constitución Política de Colombia, artículo 230: "Los jueces, en sus providencias, solo están sometidos al imperio de la ley. La equidad, la jurisprudencia, los principios generales del derecho y la doctrina son criterios auxiliares de la actividad judicial". 
Sobre este último punto la Corte Constitucional mediante sentencias C-836/2001 y C-539/2011 hizo explícita la distinción entre precedente y jurisprudencia como criterio auxiliar, aclarando que el significado del artículo 230 de la Constitución Política no se podía interpretar en el sentido que la jurisprudencia elaborada por las altas cortes constituya solo un criterio auxiliar de interpretación, sin verdadera vinculatoriedad, por razones de (i) coherencia del sistema jurídico, (ii) garantía del derecho a la igualdad, (iii) seguridad jurídica e (iv) interpretación armónica de los principios de autonomía e independencia judicial $y$ otros principios y derechos fundamentales como la igualdad (Corte Constitucional, sentencia C-539/2011). Por ende, deberá conocerse la metodología adecuada para la construcción de precedentes judiciales con el objeto de diferenciarlos de los simples criterios auxiliares, y así respaldar correctamente los argumentos que sustentarán la toma de una decisión final.

Frente a toda esta distinción tipológica cabe abordar un cuestionamiento: ¿qué nivel de aplicación práctica tiene diferenciar los tipos de precedente entre sí y el criterio auxiliar de aquellas tipologías?

Precedente de obligación absoluta. Debe entenderse como la norma jurídica o regla de derecho ${ }^{5}$-es decir, el significado del enunciado normativo (Alexy, 2002) - que ha sido fijada mediante la ratio decidendi ${ }^{6}$ de una sentencia

5 La equiparación entre reglas de derecho (o reglas jurídicas entendidas como sinónimos) y normas jurídicas la tomamos de Hart (2004). Sin embargo, acogemos como significado del término 'norma' el elaborado por Robert Alexy en su Teoría de los derechos fundamentales (2002). Esta regla de derecho bien puede encontrarse conformada por subreglas responsables de especificar el marco de aplicación de aquella o de algún calificador modal mediante el que se planteen excepciones a la regla, según enseña la teoría jurídica de Toulmin (2007).

6 La ratio decidendi como bien lo explica Bernal (2009, p. 162), "es la concreción normativa del alcance de las disposiciones jurídicas. Ella explicita qué es aquello que el derecho prohíbe, permite, ordena o habilita para cierto tipo de casos". Más adelante se explicará con más detalle el concepto de ratio decidendi y los criterios de identificación de la misma. de constitucionalidad y con la que se establece la estructura y el alcance de la proposición normativa constitucional o legal examinada. Se denomina de obligación absoluta porque no es posible apartarse del precedente. En consecuencia, el funcionario jurisdiccional habrá de cumplir con dicha "regla de derecho", sin importar que le resulte odiosa o equivocada.

Precedente de obligación semiabsoluta. Consiste básicamente en la "doctrina constitucional integradora"7 de la Corte Constitucional, por medio de la cual esta alta corporación de justicia a través de una regla jurídica (que puede estar acompañada de "subreglas" y "calificadores modales") determina el alcance de los derechos fundamentales consagrados en nuestra Carta Magna o en el bloque de constitucionalidad, y cuya producción surge únicamente en el seno de las acciones de tutelas resueltas a través del mecanismo de la eventual revisión. Al respecto puede decirse que esta tipología, jerárquicamente hablando, constituye la segunda categoría de precedente en grado de vinculatoriedad, ya que

(...) se trata de interpretar la Constitución misma, lo cual debe tener un efecto multiplicador aplicable a los casos similares o análogos, por cuanto de lo contrario se desvirtuaría su verdadera esencia y se convertiría tan solo en otra instancia de una jurisdicción (Corte Constitucional, sentencia C-539/2011).

No obstante, la obligatoriedad de dicho precedente no es absoluta, ni tampoco relativa porque posee una mayor fuerza de ligamen que la "doctrina

7 Corte Constitucional, sentencia T-292/2006: "Por doctrina constitucional integradora, se consideró aquella que ante una laguna, suple un vacío jurídico en el ordenamiento. Lo que a juicio de la sentencia que se cita precisamente la hace obligatoria, en la medida en que responde a una aplicación directa de la Constitución fundada en la interpretación autorizada de la Carta realizada por la Corte Constitucional ante la ausencia de disposición legal. De otro modo, por doctrina interpretativa se entendió la jurisprudencia constitucional en general, salvo las decisiones amparadas por cosa juzgada constitucional. Esta es criterio relevante y pauta auxiliar para los jueces, en armonía con lo establecido por el artículo 230 Superior". 
probable" de la Corte Suprema de Justicia en sus distintas salas de casación, constituyéndose por lo tanto en un precedente de obligación media, ya que aun cuando "las autoridades públicas, tanto administrativas como judiciales, están obligadas a acatar los precedentes que fije la jurisprudencia constitucional" (Corte Constitucional, sentencia C-539/2011), lo cierto es que en últimas estas podrán apartarse de dicha postura de la Corte

(...) cuando se "verifica que existen hechos en el proceso que hacen inaplicable el precedente al caso concreto", o que "existan elementos de juicio no considerados en su oportunidad por el superior, que permitan desarrollar de manera más coherente o armónica la institución jurídica", en cuyo caso se exige una "debida y suficiente justificación" (Corte Constitucional, sentencia C-539/2011).

Precedente de obligación relativa. También ha de definirse como una regla de derecho fijada mediante el empleo de una providencia judicial a través de la metodología de "caso análogo" o de la "doctrina probable" de la Corte Suprema de Justicia (como más adelante se explicará). En este sentido, se señala que tales precedentes resultan vinculantes por cuanto permiten (Corte Constitucional, sentencia C-836/2001) la coherencia del sistema jurídico, la seguridad jurídica, la interpretación armónica de los principios de autonomía e independencia judicial y otros principios y derechos fundamentales como la igualdad.

Ahora bien, el grado de obligación de dicho precedente será relativo por cuanto existirá en el funcionario jurisdiccional la posibilidad y potestad de apartarse del mismo siempre y cuando cumpla con dos cargas argumentativas (López, 2011): (i) la carga de transparencia, según la cual la autoridad judicial deberá indicar expresamente que conoce el precedente y que se apartará de él y (ii) la carga de argumentación -llamada en lógica jurídica "principio de razón suficiente" (Leibniz, 1983) ${ }^{8}$ y que se asocia íntimamente

Sobre dicho principio expresó Leibniz (1983) lo siguiente: “(..) 32. Y el de razón suficiente, en virtud con el "deber de motivación"9 consagrado en la Constitución Política- a partir de la cual el funcionario tendrá que exponer las razones jurídicas que lo llevan a considerar su criterio hermenéutico como superior al precedente judicial desechado, "ya que se prohíbe el cambio jurisprudencial discrecional” (López, 2011, p. 85), arbitrario o caprichoso dada la gran cantidad de principios constitucionales que están en juego y que fueran reseñados líneas atrás.

Esta última carga argumentativa se cumple cuando se presentan algunas de las siguientes hipótesis en torno al precedente del cual se apartará el funcionario jurisdiccional ${ }^{10}$ : (i) si se lleva a cabo un tránsito legislativo, (ii) cuando por un cambio social, político o económico se vuelva diferente la situación actual examinada de aquella en la que se produjo el precedente, (iii) si hay anfibología u oscuridad en el precedente, $y$ (iv) cuando la regla de derecho fijada en el mismo contraríe materialmente los valores, objetivos, principios y derechos en los que se fundamenta el ordenamiento jurídico.

Criterio auxiliar. Este ha de entenderse como aquel razonamiento jurídico proposicional o no, llevado a cabo por la Corte Constitucional o la Corte Suprema de Justicia que no resulta vinculante para el funcionario jurisdiccional y del cual es posible apartarse sin ningún tipo de motivación, ya que tan solo sirve de guía inter-

del cual consideramos que no podría hallarse, ningún hecho verdadero o existente, ni ninguna enunciación verdadera, sin que haya una razón suficiente para que así sea y no de otro modo" (p. 84).

9 Como exigencia del debido proceso consagrado en el artículo 29 de la Constitución Política.

10 Al respecto se sigue lo expresado en sentencia C-836/2001. Así mismo, resulta ilustrativa la sentencia SU-047/1999 que sostiene que: "la posibilidad de desligarse de los precedentes en circunstancias concretas, puede obedecer a razones como las siguientes: i) eventuales equivocaciones jurisprudenciales del pasado que hacen necesaria la corrección de una línea jurisprudencial; ii) una interpretación que habiendo sido útil y adecuada para resolver ciertos conflictos, en su aplicación actual, puede provocar consecuencias inesperadas e inaceptables en casos similares [y] iii cambios históricos frente a los que resulta irrazonable adherir a la hermenéutica tradicional". 
pretativa de la ley y su nivel de obligatoriedad es nulo por cuanto posee la misma jerarquía de ligamen que la equidad, los principios generales de derecho y la doctrina jurídica, según así se desprende del artículo 230 de la Constitución Política colombiana y conforme con el sentido que le otorga a dicho precepto nuestra Corte Constitucional ${ }^{11}$.

De igual manera resulta vital distinguir el precedente (sin importar la clase de que se trate) del criterio auxiliar, porque cuando se viola el primero por parte del funcionario jurisdiccional la providencia proferida por este pasa a convertirse en una flagrante "vía de hecho" que podría llegar a ser anulada mediante una acción de tutela interpuesta contra la misma o configurar objetivamente el delito de "prevaricato por acción"12. Por el contrario, el apartarse del simple criterio

11 En múltiples sentencias, como por ejemplo la pluricitada sentencia C-836/2001.

12 La sentencia C-335/2008 de la Corte Constitucional explicó lo siguiente: "Existen casos en los cuales un servidor público incurre en el delito de prevaricato por acción, no por desconocer simplemente la jurisprudencia sentada por una Alta Corte, considerada esta como una fuente autónoma del derecho, sino porque al apartarse de aquella se comete, a su vez, una infracción directa de preceptos constitucionales o legales o de un acto administrativo de carácter general. (...) Ahora bien, la Corte estima que a efectos de determinar si realmente un servidor público, en un caso concreto, incurrió en el delito de prevaricato por acción por desconocimiento de la jurisprudencia sentada por una Alta Corte la cual comporte, a su vez, una infracción directa de preceptos constitucionales o legales o de un acto administrativo de carácter general, resultará indicativo examinar si se está en presencia de un manifiesto alejamiento del operador jurídico de una subregla constitucional constante. En efecto, los fallos de reiteración se caracterizan por que la Corte (i) simplemente se limita a reafirmar la vigencia de una subregla constitucional perfectamente consolidada; (ii) su número resulta ser extremadamente elevado; y (iii) constituyen interpretaciones constantes y uniformes de la Constitución, la ley o un acto administrativo de carácter general, por parte del juez constitucional. En otras palabras, en los fallos de reiteración la Corte Constitucional ha acordado un sentido claro y unívoco a la 'ley', en los términos del artículo 413 del Código Penal. Situación semejante se presenta en las sentencias de unificación jurisprudencial, en la medida en que la Corte acuerde una determinada interpretación no solo a una disposición constitucional, sino a normas de carácter legal o a un acto administrativo de carácter general". auxiliar -iincluso de manera inmotivada!- no trae aparejado ningún tipo de perjuicio o responsabilidad penal o disciplinaria para el funcionario que lo haga, por cuanto ningún grado de vinculatoriedad tiene este.

\section{A. Nociones generales sobre el régimen probatorio en materia penal}

Los cambios en materia penal al régimen probatorio con ocasión del nuevo Código de Procedimiento Penal (CPP) fueron estructurales, a tal punto que algunos profesores señalaron que: "La principal característica del nuevo proceso penal colombiano está determinada por una verdadera revolución probatoria (...)" (Urbano, 2008, p. 118). Las novedades más significativas, sin desconocer las referentes a cada medio de prueba en particular, son: (i) eliminación del principio de permanencia de la prueba, base del antiguo sistema regido por la ley 600/2000; en su lugar, se implementó el principio de inmediación de la prueba; (ii) testigo de acreditación como requisito sine qua non para la incorporación de evidencia; (iii) cadena de custodia como herramienta para asegurar la conservación de la evidencia recolectada; (iv) adopción de la concepción de verdad dialéctica como fin de la prueba (prohibición absoluta de la prueba de oficio) y (v) oralidad como método de expresión para que se surta del devenir del iter probatorio (aducción, decreto, práctica y valoración de la prueba).

Antes de continuar con el análisis, vale destacar que las novedades señaladas se erigen a partir de la columna vertebral del sistema de enjuiciamiento criminal que se adoptó con la ley 906/2004: el principio acusatorio. El debate sobre el significado, alcance y límites de este principio, así como sobre sus diferencias con un sistema acusatorio, es rico en cantidad y calidad de argumentos (Illuminati, 2014); sin embargo, para efectos de este trabajo, se entenderá como la separación entre los funcionarios que ostentan el ejercicio de la acción penal (investigar y acusar) y aquellos que tienen la labor de juzgar. 


\section{B. Derechos constitucionales en tensión}

Uno de los pilares fundamentales del régimen probatorio del sistema de enjuiciamiento criminal colombiano de corte o tendencia acusatoria es la inmediación. Múltiples enunciados normativos de diferente jerarquía hacen alusión expresa a este principio de derecho procesal y probatorio: entre otros, Constitución Política de Colombia, artículo 250 inciso 4; ley 906/2004 (o CPP) artículos 6 y 379 .

Las anteriores disposiciones ponen de presente el hecho de que solo se considerará como prueba aquella en la cual se materialicen los principios de inmediación, oralidad, concentración, publicidad, confrontación y contradicción, generándose como consecuencia de ello una cláusula general de exclusión para todo lo que constituya prueba de referencia. Este fenómeno es realmente un giro copernicano en materia probatoria: se reemplazó el principio de permanencia de la prueba, propio del anterior sistema procesal regulado por la ley 600/2000, con el principio de inmediación de la prueba.

Así, las entrevistas o exposiciones (art. 347 CPP), al tener la calidad de declaraciones anteriores del testigo vertidas sin la materialización de los anteriores principios, vendrían a ser claros ejemplos de prueba de referencia documental ${ }^{13}$, cuya admisibilidad es excepcional por cuanto solo se presenta si se dan las hipótesis contenidas en el artículo 438 del CPP.

En tal sentido, una prueba de referencia (art. 437 $\mathrm{CPP}$ ) sería entonces una declaración -es decir, una aseveración sobre un hecho, susceptible de ser verdadera o falsa- realizada por fuera del juicio oral, a través de un medio documental o testimonial, y ofrecida como evidencia para

13 También puede darse el fenómeno de prueba de referencia testimonial, como lo sería un "testigo de oídas" que pretende declarar en juicio aquello de lo cual no tiene conocimiento personal (Chiesa, 2005). probar la verdad de lo aseverado ${ }^{14}$. Si el documento o la declaración testimonial encajan en las reglas de configuración de la prueba de referencia se presentaría prima facie un veto para la admisión de la evidencia, imposibilitándose su incorporación ${ }^{15}$ o producción ${ }^{16}$ dentro del juicio oral y careciendo por ende de existencia jurídica y de valor probatorio alguno ${ }^{17}$.

Empero, la no admisión de la prueba de referencia es una regla general que como se dijo líneas atrás, posee múltiples excepciones reguladas expresamente en el CPP, artículo 438. La admisibilidad de este tipo de pruebas se justifica en razón al principio de necesidad de la prueba y de igualdad material, tan presente en los Estados constitucionales contemporáneos, según el cual ante situaciones excepcionales debe responderse de manera diferente, buscando así un equilibrio entre las partes en disputa.

14 El elemento relativo a la finalidad implícita e inescindible de la prueba de referencia y consistente en "probar la verdad de lo aseverado" se deduce del artículo 437 del CPP. Así mismo, tal interpretación sería doctrina probable de la Corte Suprema de Justicia sentada en las siguientes providencias: 27477 (06-03-08), 30787 (26-03-09), 32050 (14-09-09), 32829 (17-03-10) y 34703 (14-12-11), entre otras. En cuanto al derecho comparado se tendría que según las Nuevas Reglas de Evidencia de Puerto Rico de 2009 una prueba de referencia "es una declaración que no sea la que la persona declarante hace en el juicio o vista, que se ofrece en evidencia para probar la verdad de lo aseverado" (regla 801.c) y en cuanto a las Federal Rules of Evidence nos encontramos con que "Hearsay means a statement that: (1) the declarant does not make while testifying at the current trial or hearing; and (2) a party offers in evidence to prove the truth of the matter asserted in the statement" (rule 801.c). En la doctrina: cfr. Chiesa (2005) y Vélez (2010).

15 Se "incorporan" las evidencias documentales y las evidencias físicas.

16 Se "producen" la prueba pericial, testimonial y la inspección judicial.

17 Lúcidamente afirma al respecto el maestro Chiesa: "Un aspecto central de nuestro derecho probatorio es la distinción entre admisibilidad y valor probatorio de la evidencia. [...] Si la evidencia no es admisible no tiene valor probatorio alguno y no puede ser considerada por el juzgador. Si la evidencia es admisible tendrá poco o mucho valor probatorio, pero tendrá alguno" . De igual modo, en Colombia se distingue entre "admisibilidad" de la prueba y el "valor probatorio" de la prueba únicamente admitida (entre otros, arts. 16, 380 y 381 de CPP). 
Todo esto, llevándolo al plano de la prueba pericial y particularmente del informe rendido por el perito, ha suscitado múltiples interrogantes, que serán los problemas jurídicos que se intentarán desarrollar aquí, los cuales se pueden organizar en tres grandes bloques según la temática que tratan:

1. Informe pericial y prueba de referencia: el informe como documento ¿es una prueba de referencia? ¿Dicho informe es asimilable con las declaraciones anteriores del testigo, como por ejemplo las entrevistas? De ser así, ¿sería admisible excepcionalmente por las causales del artículo 438 o tendría causales propias de admisión excepcional?

2. Presupuestos constitutivos de la prueba de referencia: ¿el informe del perito y su declaración en juicio forman en su conjunto la prueba pericial o solo la declaración del experto es lo que constituye prueba pericial? Si tanto el informe como la declaración conformaran la prueba pericial ¿se requeriría entonces la incorporación del informe como un requisito de validez para la producción de la prueba pericial?

3. Valoración probatoria de la prueba pericial: ¿puede el juez valorar para efectos de asignarle la eficacia probatoria a la prueba pericial el informe rendido por el perito previo al juicio?

$\mathrm{Al}$ respecto y según lo expuesto, pareciera en principio que el informe del perito al contener declaraciones -es decir, aseveraciones ${ }^{18}$ sobre hechos del caso- vertidas antes del juicio oral encuadraría perfectamente en los parámetros de la prueba de referencia. Desde esa óptica la admisión del mismo sería excepcional y entonces su incorporación solo podría realizarse si por ejemplo en un determinado caso muriese (art. 438 del CPP) el perito, siendo, por el contrario, innecesaria e inadmisible la incorporación de dicho

18 El perito emite opiniones y valoraciones técnicas sobre los hechos, que por supuesto en su formulación lingüistica se hacen a través de "aseveraciones". informe si el perito, al no haber fallecido, fuese a declarar a juicio, ya que únicamente con su dicho se configuraría cabalmente la prueba pericial.

\section{Doctrina}

No hay en la doctrina respuestas unánimes a las preguntas que se plantean aquí. Por el contrario, un estudio incluso somero de la literatura permite concluir que existe una clara división en torno a la naturaleza del informe pericial, a su exigencia o posibilidad de incorporación como prueba autónoma y al valor probatorio que debe tener el informe del perito si este comparece a declarar en la audiencia. Una primera postura puede encontrarse en los estudios del profesor antioqueño Luis Fernando Bedoya, quien sostiene:

De acuerdo con las normas que regulan la prueba pericial en Colombia, puede concluirse que el informe sí es admisible como evidencia, no solo por la amplia regulación de su elaboración y presentación, sino además porque el artículo 415 , en su parte final, dispone expresamente que "en ningún caso, el informe de que trata este artículo será admisible como evidencia, si el perito no declara oralmente en el juicio", de lo que se infiere que si el perito va a juicio el informe sí es admisible como evidencia.

Aunque algunos sostienen que la admisión del informe como evidencia puede ser contraria a los principios que rigen un sistema con tendencia acusatoria, puede concluirse, por lo menos en lo referente al debido proceso probatorio, que estos son observados si la parte contra la que se aduce el dictamen tiene la posibilidad de ejercer el contradictorio en la audiencia de juicio oral; ya sea contrainterrogando al perito o presentando evidencia de refutación. Además de esto, el juez tendrá inmediación sobre el medio de acreditación cuya publicidad también estará garantizada. La aceptación del dictamen como evidencia no implica que el perito no sea sometido al interrogatorio cruzado, ni 
limita el debate frente a lo expuesto por el experto, pero sí puede contribuir a que el juez tenga un mejor conocimiento del caso, así como a facilitar el trabajo previo a la emisión del sentido del fallo, lo que justifica su admisión como evidencia.

La posibilidad de admitir el informe pericial cuando el perito comparece a la audiencia del juicio oral, implica el riesgo de que con el informe sean introducidos conceptos o conclusiones no mencionados por el experto durante su intervención, lo que inclusive puede equivaler a la admisión del informe sin que el perito comparezca a la audiencia del juicio oral. Por esto, la comparecencia no ha de entenderse únicamente como la presencia física, sino esencialmente como la explicación que hace el experto de sus conclusiones, así como de su fundamento, en desarrollo de los principios de inmediación, contradicción y publicidad. El fiscal debe estar atento a este tema, para evitar que el informe o parte de este, ingrese como prueba en el evento en que el perito presentado por la defensa no se haya referido a todos los aspectos contenidos en el reporte (2008, p. 181).

Una postura contraria la asume Jaime Enrique Granados Peña:

Debe reiterarse que no constituye prueba alguna ni el informe pericial propiamente, ni el elaborado como base de la opinión pericial, si el perito no declara oralmente en el juicio. Empero, tengo duda acerca de la valoración del informe una vez haya declarado el perito, pues si bien es cierto que puede estimarse como prueba documental, si ha sido exhibida y sometida a autenticación en la audiencia, su estimación técnicamente es evidencia, no de prueba, pues esta solo sería la pericial expuesta en audiencia. En las reuniones de la comisión redactora constitucional, sostuve que el informe de policía judicial nunca puede tener valor de prueba, como se pensó en caso de asistir a audiencia la persona que lo elabora. Lo que se requiere es que declare el investigador o el perito, teniendo de presente que el informe no puede ser objeto de contrainterrogatorio $\mathrm{y}$, por tanto, no puede dársele carácter de prueba en ningún caso (2005, p. 86).

Igual posición sostiene Mildred Hartmann:

Esta misma discusión, acerca de si la prueba es la declaración del perito o es el informe escrito, podría producirse en Colombia. En efecto, el artículo 415 indica que el informe del perito debe ponerse a disposición antes del juicio (como un descubrimiento de prueba), y también indica que el informe carece de valor, si el perito no declara en el juicio. En consecuencia, ¿cuál debiera ser el valor del informe, cuando el perito sí acude a declarar? Debe entenderse que la prueba es la declaración del perito, y el informe servirá para que la contraparte prepare el contraexamen, para refrescar su memoria o para impugnar credibilidad (citada en Baytelman y Duce, 2011, p. 297).

Así las cosas, si nos atenemos a los principios de inmediación (Constitución Política artículo 250.4 y CPP artículos 15, 16, 378 y 379) y los parámetros particulares de apreciación ${ }^{19}$ de la prueba pericial se concluiría que el informe del perito, por ser una evidencia documental con un carácter de prueba de referencia inadmisible (es decir, una declaración anterior del testigo),

19 Nótese que lo que se aprecia es la declaración rendida por el perito en el juicio y no su informe, indicándose con ello, en una interpretación sistemática con las demás normas de la ley 906/2004, que dicho documento no es susceptible de ser incorporado ni valorado, sino tan solo usado con fines (art. 405 inciso $2^{\circ} \mathrm{CPP}$ ) de impugnación (art. 403.4 CPP) o refrescamiento de memoria (art. 392.d CPP). La norma específica expresa: "Art. 420. Apreciación de la prueba pericial. Para apreciar la prueba pericial, en el juicio oral y público, se tendrá en cuenta la idoneidad técnico-científica y moral del perito, la claridad y exactitud de sus respuestas, su comportamiento al responder, el grado de aceptación de los principios científicos, técnicos o artísticos en que se apoya el perito, los instrumentos utilizados y la consistencia del conjunto de respuestas". 
no podría ser incorporado al juicio oral para integrarse con el testimonio, ya que ni sería una prueba documental directa y autónoma ni tampoco su existencia se haría necesaria para producir satisfactoriamente la prueba pericial, puesto que serían figuras jurídicas totalmente separables (como son separables por ejemplo la entrevista que toma el policía judicial de la declaración que rinde el testigo en el juicio oral, sin que se requiera para la formación de esta última la preexistencia de dicha declaración anterior).

Sin embargo, tomar en específico los enunciados normativos encargados de regular el informe del perito, hace que la situación se torne problemática y surja una interpretación diversa a la realizada líneas atrás como sería la siguiente: el artículo 415 del CPP nos dice que "en ningún caso, el informe de que trata este artículo será admisible como evidencia, si el perito no declara oralmente en el juicio", lo cual a contrario sensu indicaría claramente que si el perito sí declara se podría admitir o incorporar el informe pericial dentro del proceso penal, como bien señala Bedoya (2008).

Además, tan fundamental resulta el informe pericial que el mismo artículo 415 ordena la realización de este para la edificación de la prueba pericial cuando expresa que "toda declaración de perito deberá estar precedida de un informe resumido en donde se exprese la base de la opinión pedida por la parte que propuso la práctica de la prueba", lo cual ha conllevado que inclusive algún sector jurisprudencial ${ }^{20}$ asimile equivocadamente el informe del perito con la base $^{21}$ de la opinión pericial.

$20 \quad$ "El informe pericial (artículo 415 Ley 906 de 2004) es la base de la opinión pericial, generalmente expresada por escrito, que contiene la ilustración experta o especializada solicitada por la parte que pretende aducir la prueba" (sentencia del 21 de febrero de 2007, Rad. 25.920, CSJ, Sala de Casación Penal).

21 El fundamento de la opinión pericial definitivamente no es el informe que rinde el perito ya que "(...) la 'base' de la opinión pericial se refiere a la base fáctica de la opinión o inferencia pericial, esto es los hechos o datos que usa el perito para emitir sus conclusiones. No se trata de la base científica de la opinión, o la literatura que sirve de apoyo a las conclusiones del perito" (Chiesa, 2005, p. 517)
En contra del último criterio hermenéutico sería viable argumentar que (i) el informe que contiene la base de la opinión pericial no necesariamente se debe rendir por escrito antes de la declaración que realizará el perito en juicio oral, y (ii) que es un yerro asimilar siempre la palabra informe con un documento, ya que lingüísticamente este sería la "descripción, oral o escrita, de las características y circunstancias de un suceso o asunto" (Diccionario de la Real Academia Española, 2001), lo cual llevado al terreno de la prueba pericial implicaría agregarle que además de la descripción habrían de incluirse "valoraciones que requieran conocimientos científicos, técnicos, artísticos o especializados" (art. 405 CPP).

Todo lo anterior, encontraría apoyo además en el siguiente enunciado normativo: "Las partes solicitarán al juez que haga comparecer a los peritos al juicio oral y público, para ser interrogados y contrainterrogados en relación con los informes periciales que hubiesen rendido, o para que los rindan en la audiencia" (art. 412 CPP).

De este panorama y maremágnum de preguntas es que ha surgido el problema jurídico con el que encabezamos el presente artículo: ¿debe y puede ser incorporado en juicio oral el informe del perito para que se produzca satisfactoriamente la prueba pericial o esta última solo se produce con el solo dicho del testigo experto?

\section{Línea jurisprudencial}

En relación con la Corte Constitucional se tiene que ningún pronunciamiento se ha llevado a cabo en torno a los problemas jurídicos que se estudian en la presente investigación. Por su parte, la Sala de Casación Penal de la Corte Suprema de Justicia se ha pronunciado respecto al tema de la prueba pericial en $17^{22}$ oportunidades.

$22 \quad 25920$ (21-02-07), 26128 (11-04-07), 27536 (06-0907), 28862 (20-02-08), 29609 (17-09-08), 30214 (17-09-08), 30021 (02-12-08), 30480 (03-06-09), 31475 (17-06-09), 31950 (19-08-09), 30355 (1507-09), 31981 (14-09-09), 32604 (11-11-09), 32868 (10-03-10), 34434 (09-12-10), 36827 (21-09-11) y AP4442-2014 (30-07-2014). 
Para hacer el análisis jurisprudencial se utilizará la metodología propuesta por el ilustre profesor Diego López Medina en su libro El derecho de los jueces (2011). Por lo tanto, solamente se emplearán para la construcción de las líneas jurisprudenciales aquellas providencias que a través de reglas de ratio decidendi hayan tocado específicamente la respuesta a cada uno de los problemas jurídicos planteados.

En la tabla 1 se visualiza el comportamiento jurisprudencial de la Sala de Casación Penal en torno a los diversos problemas jurídicos en que se puede descomponer el interrogante que encabeza el artículo.

Tabla 1. Primer problema jurídico

¿Es obligatorio, como requisito de legalidad, incorporar en el juicio oral el informe escrito del perito para que se configure la prueba pericial?

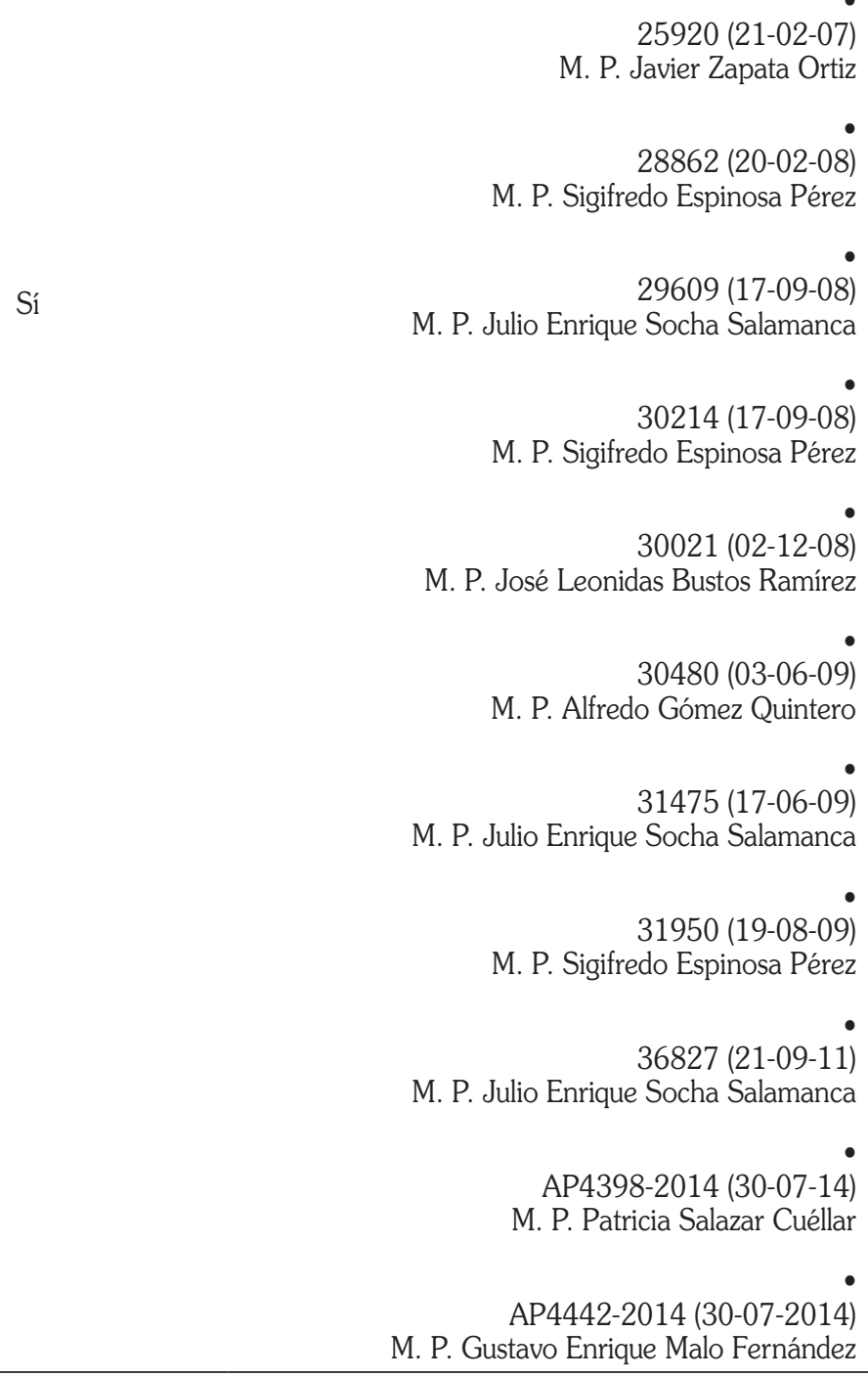

Fuente: elaboración propia.

Bogotá, D. C., Colombia - Volumen XX - Número 39 - Enero - Junio 2017 - ISSN 0121-182X 
Esto implicaría que la prueba pericial se produce únicamente con la declaración que da el perito en juicio oral, sin que se requiera la incorporación del informe escrito para su configuración.

Salvo la pequeña variación del radicado 30021 (02-12-08), es posible afirmar que de manera pacífica la Sala de Casación Penal ha considerado que la prueba pericial solo la constituye la declaración del perito, sin que se integre a la misma el informe escrito cuya tendencia en la praxis judicial es a la incorporación de este. Inclusive en técnica de casación, la Corte sostiene que lo que debe atacarse como prueba es la declaración del perito y no el informe, llegando a aseverar lo siguiente:

Lo antes expuesto permite concluir que como el reporte escrito vertido por el perito es apenas la base de su dictamen, no tiene la calidad de medio de prueba autónomo, y en consecuencia en sede de casación es un garrafal desacierto impugnarlo como si de tal condición estuviese revestido, pues, lo ajustado a derecho, según las citadas disposiciones, es dirigir la crítica a la prueba pericial misma, vale decir, respecto de la declaración testimonial que rinde el perito en la audiencia pública, ya que es en esa oportunidad cuando, al ser interrogado y contrainterrogado por las partes acerca del contenido del informe, el experto ayuda a comprender el tema especializado sobre el cual versa su opinión (31475 [17-06-09]).

Aun cuando la posición de la Sala de Casación Penal es que no resulta jurídicamente viable incorporar el informe, porque la prueba pericial la constituye es la declaración del perito, lo cierto es que tampoco se atreve la alta corporación a afirmar que el hacerlo generaría una violación flagrante de los principios de inmediación y contradicción de la prueba. Tan solo se limita a indicar lo que debe efectuarse en relación con la producción de la prueba, sin fijar las consecuencias adversas que podrían derivarse de incumplir con tales lineamientos; tampoco señala lo atinente a la eficacia demostrativa del informe pericial.
Sin embargo, es posible sostener al respecto que si un informe escrito del perito es incorporado ilegalmente (ilegal ${ }^{23}$ en cuanto no sería admisible como prueba autónoma en el juicio oral, por ser una declaración anterior del testigo y en consecuencia una prueba de referencia sobre la cual no se han dado las causales del art. 438 del $\mathrm{CPP}$ ) perfectamente podría aplicarse sobre el mismo la cláusula de exclusión, ya que según el artículo 23 de la ley 906/2004 "toda prueba obtenida con violación de las garantías fundamentales será nula de pleno derecho, por lo que deberá excluirse de la actuación procesal".

En este caso, con la admisión de un informe escrito que per se constituye prueba de referencia ${ }^{24}$ inadmisible se estarían violentando el

23 Sobre la distinción entre prueba ilegal y prueba ilícita la Corte Suprema de Justicia, en Sala de Casación Penal, tiene sentada la siguiente doctrina probable o precedente de obligación relativa: "(...) 4. El artículo 29 de la Constitución Política consagra la regla general de exclusión al disponer que: 'Es nula de pleno derecho, la prueba obtenida con violación del debido proceso'. La exclusión opera de maneras diversas y genera consecuencias distintas dependiendo si se trata de prueba ilícita o prueba ilegal. 4.1 Se entiende por prueba ilícita la que se obtiene con vulneración de los derechos fundamentales de las personas, entre ellos la dignidad, el debido proceso, la intimidad, la no autoincriminación, la solidaridad íntima; y aquellas en cuya producción práctica o aducción se somete a las personas a torturas, tratos crueles, inhumanos o degradantes, sea cual fuere el género o la especie de la prueba así obtenida. La prueba ilícita debe ser indefectiblemente excluida y no podrá formar parte de los elementos de convicción que el juez sopese para adoptar la decisión en el asunto sometido a su conocimiento, sin que pueda anteponer su discrecionalidad ni la prevalencia de los intereses sociales. (...) 4.2 La prueba ilegal se genera cuando en su producción, práctica o aducción se incumplen los requisitos legales esenciales, caso en el cual debe ser excluida, como lo indica el artículo 29 Superior. En esta eventualidad, corresponde al juez determinar si el requisito legal pretermitido es esencial y discernir su proyección y trascendencia sobre el debido proceso, toda vez que la omisión de alguna formalidad insustancial, por sí sola no autoriza la exclusión del medio de prueba" (providencias 18103 [05-03-05], 19219 [09-02-06] y 32193 [21-10-09] entre muchas otras).

24 El informe es una declaración realizada fuera del juicio oral que se ofrecería como evidencia para probar la verdad de lo aseverado si se pretendiese incorporar el mismo. 
Tabla 2. Segundo problema jurídico

¿La prueba pericial es únicamente la declaración que da el perito en audiencia pública?

25920 (21-02-07)

M. P. Javier Zapata Ortiz

28862 (20-02-08)

M. P. Sigifredo Espinosa Pérez

Sí, únicamente la prueba pe-

ricial es lo declarado por el 29609 (17-09-08)

perito en audiencia de juicio M. P. Julio Enrique Socha Salamanca

oral, ya que el informe solo

sirve para refrescar memoria

o impugnar credibilidad
30214 (17-09-08)

M. P. Sigifredo Espinosa Pérez
No, la prueba pericial es una simbiosis entre el informe escrito y la declaración del perito en juicio y ambos deben valorarse

30021 (02-12-08)

M. P. José Leonidas Bustos Ramírez

31475 (17-06-09)

M. P. Julio Enrique Socha Salamanca

31950 (19-08-09)

M. P. Sigifredo Espinosa Pérez

36827 (21-09-11)

M. P. Julio Enrique Socha Salamanca

AP4398-2014 (30-07-14)

M. P. Patricia Salazar Cuéllar

AP4442-2014 (30-07-2014)

M. P. Gustavo Enrique Malo Fernández

Fuente: elaboración propia. 
Tabla 3. Tercer problema jurídico

¿Es jurídicamente posible incorporar el informe escrito del perito para integrarlo con la declaración del experto?

25920 (21-02-07)

M.P. Javier Zapata Ortiz

$28862(20-02-08)$

M. P. Sigifredo Espinosa Pérez

Sí, resulta jurídicamente viable la incorporación del informe pericial para integrarlo con el dicho del perito, lo cual no significa que ello sea obligatorio
29609 (17-09-08)

M. P. Julio Enrique Socha Salamanca

30214 (17-09-08)

M. P. Sigifredo Espinosa Pérez

$30021(02-12-08)$

M. P. José Leonidas Bustos Ramírez

31475 (17-06-09)

M. P. Julio Enrique Socha Salamanca

31950 (19-08-09)

M. P. Sigifredo Espinosa Pérez

36827 (21-09-11)

M. P. Julio Enrique Socha Salamanca

33651 (18-05-2011)

M. P. Javier Zapata Ortiz

AP4442-2014 (30-07-2014)

M. P. Gustavo Enrique Malo Fernández

AP4398-2014 (30-07-14)

M. P. Patricia Salazar Cuéllar
No es jurídicamente viable incorporar el informe pericial ya que al estar contenido en un documento escrito constituiría, por sí solo, una declaración anterior del testigo con calidad de prueba de referencia inadmisible

Fuente: elaboración propia.

debido proceso y los principios de inmediación, contradicción y confrontación. Ahora bien, una vez excluido el informe, este carecería de cualquier valor probatorio y por ende, no podría incluirse como respaldo argumentativo en la motivación de la sentencia condenatoria o absolutoria dictada.

\section{Enunciación de las reglas de derecho como precedente y respuesta al problema jurídico planteado}

La Corte Suprema de Justicia en Sala de Casación Penal fijó como regla de derecho, mediante 
doctrina probable $e^{25}$ para solucionar la pregunta en torno a si el informe escrito del perito debe ser incorporado en audiencia de juicio oral, la siguiente:

El informe escrito del perito y la prueba pericial son diferentes, por lo que esta última se produce y configura únicamente con "la declaración testimonial que hace el perito en la audiencia pública cuando es interrogado y contrainterrogado sobre el contenido del informe técnico científico"(25920 [21-02-07]) ya que "el informe en efecto es un documento, pero no es conducente para demostrar la teoría del caso de la Fiscalía, por expresa limitación legal" (30214 [17-09-08]) concluyéndose entonces que "esos informes no son la prueba, sino un germen de la misma y si bien, constan en un documento, tampoco pueden ser aducidos como tales" (30214 [17-09-08]). A partir de dichas reglas encontramos las siguientes subreglas de la Corte Suprema de Justicia:

Subregla $1^{a}$ : las críticas de valoración y legalidad deben ir dirigidas contra la prueba pericial y no contra el informe escrito del perito (25920 [2102-07], 29609 [17-09-08], 30214 [17-09-08], 31475 [17-06-09], 31950 [19-08-09], 31981 [14-09-09] y 36827 [21-09-11]).

Subregla $2^{\underline{a}}$ : las funciones que cumple el informe escrito son las siguientes: (i) puede servir en la etapa investigativa para adoptar algunas determinaciones (25920 [21-02-07]), (ii) debe integrarse al proceso de descubrimiento probatorio, admitirse ${ }^{26}$ como evidencia con destino

25 La regla que a continuación se enuncia y que es reiterada (con pequeñas variaciones gramaticales o a veces de manera literal) por la Corte Suprema de Justicia, la hallamos en las siguientes providencias: 25920 (2102-07), 29609 (17-09-08), 30214 (17-09-08), 31475 (17-06-09), 31950 (19-08-09), 31981 (14-09-09) y 36827 (21-09-11).

26 Acá el término admisión no lo debemos confundir con el de incorporación. La admisión a la que hace alusión la Corte Suprema de Justicia es la concerniente a la que tiene lugar en la audiencia preparatoria y que consiste en autorizar la futura práctica de la prueba pericial que se producirá en el juicio oral solamente con "la declaración testimonial que hace el perito en la audiencia pública a la futura prueba pericial y debe ser real y efectivamente conocido por la contraparte, para que pueda diseñar una estrategia, si fuese de su interés (25920 [21-02-07], 29609 [17-09-08], 30214 [17-09-08], 31950 [19-08-09] y 36827 [21-09-11]) y preparar el contrainterrogatorio, (iii) puede servir también para refrescar la memoria del perito (25920 [1-02-07] y 30214 [17-09-08]) y (iv) para ponerle de presente contradicciones entre lo anotado en el informe y lo declarado actualmente en la audiencia del juicio oral (25920 [21-02-07], 28862 [20-0208], 30214 [17-09-08] y 36827 [21-09-11]).

Subregla $3^{a}$ : el informe escrito del perito, dado su ostensible carácter accesorio, ningún valor tiene si el experto no concurre a la audiencia de juicio oral a rendir de viva voz el dictamen, como lo postula el inciso segundo del artículo 415 de la ley 906/2004, o que puede presentarse el dictamen sin el documento, tal cual lo consagra el artículo 412 de la misma ley (25920 [21-02-07], 28862 [20-02-08], 29609 [17-09-08], 30214 [17-09-08], 30480 [03-06-09], 31475 [17-06-09] y 31950 [1908-09]). En otras palabras, la comparecencia del perito ante la audiencia de juicio oral es un requisito de existencia insoslayable de la prueba pericial.

Frente a la imposibilidad de que el perito concurra a la audiencia existen los siguientes calificadores modales ${ }^{27}$ para la subregla $3^{\mathrm{a}}$, propuestos por la Sala de Casación Penal de la Corte Suprema de Justicia:

cuando es interrogado y contrainterrogado sobre el contenido del informe técnico científico" (25920 [2102-07]).

27 El calificador modal $(\mathrm{Q})$ en la teoría de la argumentación jurídica de Toulmin (2007) precisa hasta qué punto llega la "garantía" -el respaldo de la regla- o la subregla, su especificación y también constituye la excepción a la regla. Por lo tanto, un calificador modal, en términos más sencillos, vendría a ser la determinación particular de aplicación de una subregla y en algunos casos el planteamiento de una excepción para la misma.

Bogotá, D. C., Colombia - Volumen XX - Número 39 - Enero - Junio 2017 - ISSN 0121-182X 
Primer calificador modal (Q1): en principio ${ }^{28}$, "la ley habilita mecanismos para que aún en la lejanía o bajo padecimientos de salud que le impidan desplazarse, el perito pueda rendir su versión oral, conforme lo establecido por el artículo 419 del CPP" (Corte Suprema de Justicia, Sala de Casación Penal, 2013, p. 17) ${ }^{29}$.

Segundo calificador modal (Q2): cuando se presente una situación de imposibilidad absoluta de que el perito pueda rendir su versión en audiencia pública -ha fallecido, se ignora su paradero, no cuenta ya con facultades mentales para el efecto, solo por vía enunciativa en el ánimo de citar ejemplos pertinentes-, y a la pérdida o desnaturalización del objeto sobre el cual debe realizarse el examen o experticia, es posible que acuda a rendir el peritaje una persona diferente de aquella que elaboró el examen y presentó el informe (30214 [17-0908] y 30480 [03-06-09]).

Ante la imposibilidad absoluta de comparecencia del perito inicial a declarar en la audiencia de juicio oral, se puede realizar un nuevo examen al objeto de interés para el proceso por nuevo perito, lo que comporta un nuevo informe pericial. Este informe puede ser rendido por escrito o en audiencia conforme lo dispuesto por el artículo 412 de la ley 906/2004, según el cual los peritos pueden ser citados por el juez, a instancia de las partes, para ser interrogados y contrainterrogados en relación con los informes "o para que los rindan en la audiencia".

Tercer calificador modal (Q3): sin embargo, si ninguna de estas dos opciones se hace factible -no se halla disponible el perito para rendir su dictamen y no es posible efectuar otro examen al objeto o fenómeno-, estima la Corte el cami-

\footnotetext{
28 Véase comentario anterior.

29 "Si el perito estuviera físicamente impedido para concurrir a la audiencia pública donde se practicará la prueba, de no hallarse disponible el sistema de audio vídeo u otro sistema de reproducción a distancia, esta se cumplirá en el lugar en que se encuentre, en presencia del juez y de las partes que habrán de interrogarlo" (art. 419 del CPP)
}

no de la excepcionalidad, dentro de un criterio de razonabilidad y ponderación que tenga en cuenta los derechos de las partes -recuérdese, dentro del presupuesto adversarial y de igualdad de armas, tanto la fiscalía como la defensa pueden, y deben, presentar este tipo de pruebas para favorecer su teoría del caso- y la esencia misma del proceso penal, representada por la norma rectora consagrada en el artículo 10 de la ley 906/2004:

La actuación procesal se desarrollará teniendo en cuenta el respeto a los derechos fundamentales de las personas que intervienen en ella y la necesidad de lograr la eficacia del ejercicio de la justicia. En ella los funcionarios judiciales harán prevalecer el derecho sustancial.

Debe aceptarse que ese informe, entendido como base de la atestación pericial, sirva de soporte al dictamen que rinda un experto distinto a aquel que lo elaboró (30214 [17-09-08] y 30480 [03-06-09]).

Subregla 4ㅁ: los reconocimientos que hacen los médicos forenses a las personas que han padecido lesiones con ocasión de un delito y que son consignados en un documento constituyen informes técnicos científicos que tienen el carácter de informe pericial, requiriéndose para la producción de la prueba la concurrencia del experto a juicio para que declare sobre dicho reconocimiento (30214 [17-09-08] y 36827 [21-09-11]).

Subregla $5^{\underline{a}}$ : si bien el informe del experto puede estar contenido en un documento, este no es prueba documental y el mismo constituye, estrictamente prueba pericial ${ }^{30}$, y como tal, el

30 Para evitar confusiones sobre el significado de la subregla 5a deben hacerse las siguientes precisiones: (i) el término lingüístico "informe" no es siempre utilizado por la Corte Suprema de Justicia ni por el legislador como documento escrito, sino que es entendido más bien como la descripción o valoración técnica o científica, oral o escrita, de las características y circunstancias de un suceso o asunto, así por ejemplo el artículo 412 cuando señala que "las partes solicitarán al juez que 
perito debe ser citado al debate público y oral con el fin de ser interrogado y contrainterrogado en relación con su concepto o para que lo rinda directamente en el juicio (5920 [21-02-07], 29609 [17-09-08], 30214 [17-09-08], 31475 [17-06-09], 31950 [19-08-09], 31981 [14-0909] y 36827 [21-09-11]).

Calificador modal único de la subregla 5aㅡ (Qo): los peritos pueden concurrir a la audiencia tanto para sustentar el informe previamente presentado, como para rendirlo allí, de lo cual se deriva que ninguna irregularidad existe, en principio, cuando el perito no presenta el informe o resumen previo, si lo que se busca es precisamente hacerlo concurrir a la audiencia para que allí, sometido a interrogatorio y contrainterrogatorio, realice esa tarea (31981 [14-09-09]).

Subregla $6^{\underline{a}}$ : los informes técnico-mecánicos hechos por los peritos adscritos a la Policía Nacional, o en general cualquier entidad pública o particular contiene una serie de valoraciones, descripciones y conceptos que para convertirse en prueba pericial y lograr ser introducidos en juicio oral se requiere que el experto vaya a juicio a declarar sobre dichos aspectos (31981 [14-09-09]).

\section{Conclusiones}

En relación con la tipología de precedente deberán hacerse las siguientes precisiones para efectos de la invocación jurisprudencial que

\footnotetext{
haga comparecer a los peritos al juicio oral y público, para ser interrogados y contrainterrogados en relación con los informes periciales que hubiesen rendido, o para que los rindan en la audiencia" está claramente indicando que el informe pericial puede darse por escrito o rendirse oralmente en audiencia pública, $y$ (ii) cuando la Corte apunta que el informe no es evidencia documental sino prueba pericial, lo que quiere significar es que el "documento" -si lo hay- apenas es un "germen" (30214 [17-09-08]) de aquello que puede considerarse como prueba y que por lo tanto cuando este informe "se rinda en audiencia" (art. 412 CPP) es que ya se contará con una verdadera prueba que será pericial y no documental.
}

hagan los operadores jurídicos de las reglas y subreglas citadas:

1. Existe doctrina probable $e^{1}$-es decir, precedente de obligación relativa- en torno a la regla de derecho de la Corte Suprema de Justicia, según la cual no es obligatorio ni procedente la incorporación del informe escrito en audiencia de juicio oral ${ }^{2}$, ya que la prueba pericial se produce satisfactoriamente tan solo con la declaración del perito en audiencia pública.

2. De las subreglas reseñadas las siguientes constituyen doctrina probable: $1^{\mathrm{a}}, 2^{\mathrm{a}}, 3^{\mathrm{a}}$ y $5^{\mathrm{a}}$.

3. De las subreglas reseñadas las siguientes constituyen mero criterio auxiliar ${ }^{3}: 4^{\underline{a}}$ y $6^{\underline{a}}$.

1 Se denomina doctrina probable a aquella regla o subregla de derecho reiterada en tres oportunidades. Ley 153/1887, artículo 10. Artículo subrogado por el artículo 4 de la ley 169/1889 que dispone que: "Tres decisiones uniformes dadas por la Corte Suprema, como tribunal de casación, sobre un mismo punto de derecho, constituyen doctrina probable".

2 Resulta fundamental no confundir el informe escrito que rinde el perito (y al cual nos estamos refiriendo en el presente escrito) con el informe del policía judicial o investigador (art. 209 del CPP), ya que en el primero se consigna la base de la opinión pericial, mientras que en el segundo tan solo se rinde la descripción de una actividad policial y por lo tanto, ningún valor probatorio tiene ni tendrá al ser una clara prueba de referencia inadmisible. Sobre el hecho de que el informe de policía judicial o investigador no se puede incorporar ni constituye prueba, existe doctrina probable uniforme y pacífica desde la regulación de la ley 600/2000 inclusive: 17247 (27-03-01), 16182 (04-11-02), 30987 (07-0710), 33920 (11-04-12), entre muchas otras. Así mismo, estos informes no se deben confundir con las actas de reconocimiento fotográfico o en fila de personas que tampoco se pueden incorporar ni constituyen prueba, según múltiple jurisprudencia de la Sala de Casación Penal: 16920 (12-09-02), 26276 (29-08-07), 31614 (22-07-09), 32277 (24-02-11), 35466 (09-03-11) y 38773 (27-02-13), entre muchas otras.

3 El criterio auxiliar no posee ningún grado de vinculatoriedad y por lo tanto, el juez puede apartarse del mismo sin necesidad de motivación alguna, a diferencia de la doctrina probable que constituye un precedente de obligación relativa y por ello, en principio vincula de manera vertical y horizontal. En esos casos, si el juzgador desea apartarse de dicha doctrina deberá cumplir con las cargas argumentativas que ha dispuesto la sentencia C-836/2001 y que expusimos aquí. 
4. Todos los calificadores modales (tanto de la subregla $3^{\underline{a}}$ como de la subregla $5^{\text {a }}$ ) se constituyen tan solo en meros criterios auxiliares.
Graficando las conclusiones anteriores tendríamos que en lo relativo a la prueba pericial su estructura funcional es la que se muestra en la gráfica 1.

Gráfica 1. Estructura de la prueba pericial

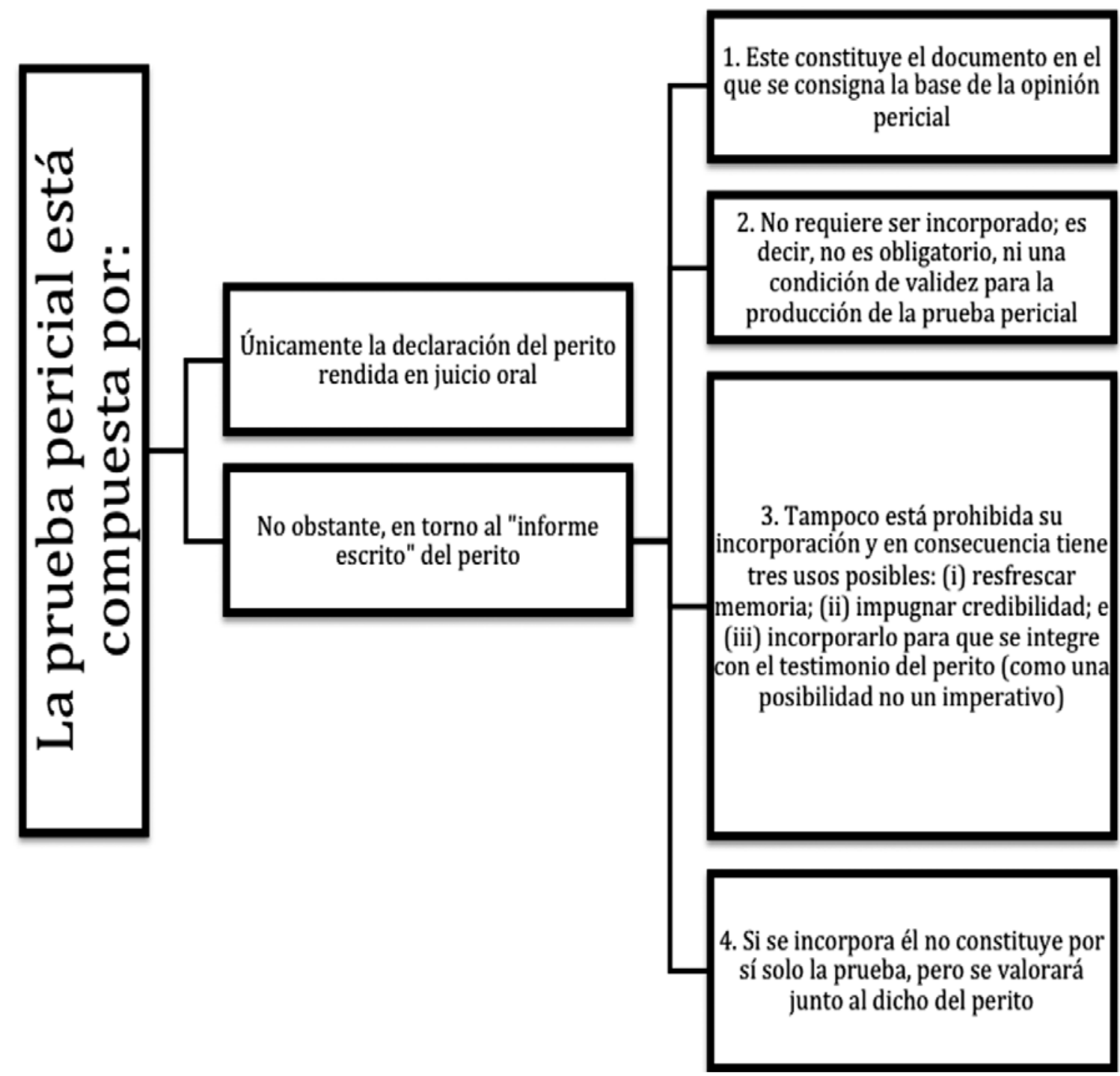

Fuente: elaboración propia. 


\section{Referencias}

Alexy, R. (2002). Teoría de los derechos fundamentales. Madrid: Centro de Estudios Políticos y Constitucionales.

Baytelman, A. \& Duce, J. M. (2011). Litigación penal, juicio oral y prueba. Bogotá: Grupo Editorial Ibáñez.

Bedoya, L. F. (2008). La prueba en el proceso penal colombiano. Bogotá: Fiscalía General de la Nación.

Bernal, C. (2009). El neoconstitucionalismo y la normatividad del derecho. Bogotá: Universidad Externado de Colombia.

Chiesa, L. E. (s. f.). La prueba documental en el sistema adversarial de Estados Unidos y Puerto Rico. I. C. Procesal. Memorias del XXXI Congreso de Derecho Procesal .

Chiesa, L. E. (2005). Tratato de derecho probatorio. Vol. II. San Juan: Publicaciones JTS.

Granados, J. E. (2005). La prueba pericial y la prueba novel en el marco del nuevo proceso penal en Colombia. Revista de Derecho Penal Contemporáneo, 75-98.

Hart, H. (2009). El concepto del derecho. Buenos Aires: Abeledo-Perrot.

Illuminati, G. (2014). Sistema acusatorio y adversary system. I. C. Procesal, XXXV Congreso Colombiano de Derecho Procesal. Cartagena: Universidad Libre.

Leibniz, G. (1983). Monadología. Buenos Aires: Ediciones Orbis S. A.

López, D. E. (2011). El derecho de los jueces (2 $2^{\mathrm{a}}$ ed.). Bogotá: Legis Editores S. A.

Toulmin, S. E. (2007). Los usos de la argumentación. Barcelona: Ediciones Península.

Urbano, J. J. (2008). La nueva estructura probatoria del proceso penal. Bogotá: Ediciones Jurídicas Andrés Morales.

Vélez, E. (2010). La prueba de referencia y sus excepciones. San Juan: Inter Juris.

\section{Normativa colombiana}

República de Colombia. (1887). Ley 153.

República de Colombia. (1991). Constitución Política de Colombia.

República de Colombia. (2004). Ley 906.

\section{Normativa foránea}

Estados Unidos de Norte América. Federal rules of evidence.

Puerto Rico. (2009). Reglas de evidencia.

\section{Jurisprudencia}

Corte Suprema de Justicia de Colombia. (2001). Sentencia 17247.

Corte Suprema de Justicia de Colombia. (2002). Sentencia 16920.

Corte Suprema de Justicia de Colombia. (2002). Sentencia 16182.

Corte Suprema de Justicia de Colombia. (2005). Sentencia 18103.

Corte Suprema de Justicia de Colombia. (2006). Sentencia 19219.

Corte Suprema de Justicia de Colombia. (2007). Sentencia 25920.

Corte Suprema de Justicia de Colombia. (2007). Sentencia 26128.

Corte Suprema de Justicia de Colombia (2007). Sentencia 26276.

Corte Suprema de Justicia de Colombia. (2007). Sentencia 27536.

Corte Suprema de Justicia de Colombia. (2008). Sentencia 28862.

Corte Suprema de Justicia de Colombia. (2008). Sentencia 29609.

Corte Suprema de Justicia de Colombia. (2008). Sentencia 30217.

Corte Suprema de Justicia de Colombia. (2008). Sentencia 30021. 
Corte Suprema de Justicia de Colombia. (2009). Sentencia 30480.

Corte Suprema de Justicia de Colombia. (2009). Sentencia 31475.

Corte Suprema de Justicia de Colombia. (2009). Sentencia 30355.

Corte Suprema de Justicia de Colombia. (2009). Sentencia 31614.

Corte Suprema de Justicia de Colombia. (2009). Sentencia 31950.

Corte Suprema de Justicia de Colombia. (2009). Sentencia 31981.

Corte Suprema de Justicia de Colombia. (2009). Sentencia 32193.

Corte Suprema de Justicia de Colombia. (2009). Sentencia 32604.

Corte Suprema de Justicia de Colombia. (2010). Sentencia 32868.
Corte Suprema de Justicia de Colombia. (2010). Sentencia 30987.

Corte Suprema de Justicia de Colombia. (2010). Sentencia 34434.

Corte Suprema de Justicia de Colombia. (2011). Sentencia 35466.

Corte Suprema de Justicia de Colombia. (2011). Sentencia 36827.

Corte Suprema de Justicia de Colombia. (2011). Sentencia 33920.

Corte Suprema de Justicia de Colombia. (2011). Sentencia 38773.

Corte Suprema de Justicia de Colombia. (2011). Sentencia 36827.

Corte Suprema de Justicia de Colombia. (2014). Sentencia AP4442-2014.

Corte Suprema de Justicia de Colombia. (2014). Sentencia AP4398-2014. 